\title{
Role of Analytical Techniques in the Standardization of A Dermoprotective Polyherbal Formulation - Dermoshine
}

\author{
Meena $\mathrm{J}^{1 *}$, Thirugnanasambantham $\mathrm{P}^{2}$, Ramasamy $\mathrm{V}^{3}$, Narayanan $\mathrm{N}^{4}$, Kuppuswamy $\mathrm{T}^{5}$ \\ ${ }^{1}$ Research Scholar, Periyar Maniammai University, Thanjavur \\ ${ }^{2}$ Head R\&D, Rumi Herbals Pvt Ltd, Chennai \\ ${ }^{3}$ Dean Research, Periyar Maniammai University, Thanjavur \\ ${ }^{4}$ Director, Jaya college of Pharmacy, Chennai \\ ${ }^{5}$ Senior Scientist, Rumi Herbals Pvt Ltd, Chennai.
}

Received: May 25, 2015; Accepted: June 14, 2015; Published: July 01, 2015

*Corresponding author: Mrs. J Meena, No 327, 4th Cross street, Mohan Ram Nagar, Mugappair East, Chennai - 600037, Tamil Nadu, India, Phone: 9444164185; Email: rajusudha2001@hotmail.com.

\begin{abstract}
Quality control and standardization of herbal medicines involve several steps. However, the source and quality of raw materials play a pivotal role in guaranteeing the quality and stability of herbal preparations. Development of authentic analytical methods which can reliably profiling the phytochemical composition, including qualitative and quantitative analyses of bioactive compounds play a major challenge to scientists. In this research work, Dermoshine a polyherbal dermoprotective, In-house preparation has been taken to standardize on the basis of organoleptic and physicochemical properties. All the test parameters are found to be within normal limits.
\end{abstract}

Keywords: Quality control Parameters; Poly herbal formulation; Dermoprotective effect

others, skin lighteners and sun-screen agents are play a definite role. In vitro scientific studies have shown that plants possess the ability to reduce antioxidant levels and inhibit hyaluronidase, collagenase, elastase and tyrosinase activity [1-3]. Collagen, one of the major building blocks of the skin, is the main component of connective tissue, hair and nails [4]. It is responsible for the elasticity and strength of the skin and maintains its flexibility. Hyaluronic acid has the capacity in retaining the moisture of the skin, as well as its structure and elasticity. It also facilitates the exchange of nutrients and waste products and is involved in rapid tissue proliferation, regeneration and repair $[1,5]$.

At present situation number of external products is available for various skin disorders but limited formulations are utilized internally. For curing skin disorders not only external but also internal drugs are required, which give better results in combination. Based on this background we have formulated a polyherbal formulation which acts as antioxidant, antiaging, antiwrinkling, skin whitening, antiacne and antidandruff activity. The polyherbal formulation was formulated for dermoprotective activity by using traditional medicinal plants such as Andrographis paniculata (whole plant), Aristolochia bracteata (Leaves) Phyllanthus amarus (Whole plant), Azadirachta indica (Leaves) Curcuma longa (Rhizome) and Hemidesmus indicus (Root)

Standardization is an important aspect for maintaining and assessing the quality and safety of the polyherbal formulation as they are combinations of more than one herb to attain the desired therapeutic effect [6]. Standardization minimizes batch to batch variation; assure safety, efficacy, quality and acceptability of the polyherbal formulations [7].

The present study was undertaken to develop a quality control parameters for a marketed dermoprotective polyherbal by using various organoleptic and physiochemical parameters specified by Ayurveda, Siddha pharmacopoeias and WHO guidelines [8, 9]. The formulation was manufactured by Rumi Herbals Pvt. Ltd, a GMP certified company and marketed by Rohini Global Marketing Pvt Ltd. Chennai.

\section{Materials And Methods}

Plant Materials: The Plant Materials As Mentioned In The Introduction Were Procured From Local Herbal Vendors In Chennai With Individual Quality Control Report.

Physical Examination: All the dry plant materials were examined physically by spreading in polythene sheet, cleaning was done by experienced people.

Grinding And Sieving: The Plant Materials Were Ground Into Coarse Powder With The Help Of Electric Grinder. Sieving Was Done To Get Uniform Granules By Using Sieve.

No. 40.

Raw Material Quality Assessment: The Below Mentioned Parameters Were Assessed As Per The Standards Provided In Ayurveda And Siddha Pharmacopeias, Govt. Of India. 
Foreign Matters: Foreign matter contains other plant parts, mineral or mud, sand admixtures, organisms, products of organism and other than the named material. Weighed out 100 $\mathrm{g}$ of the drug sample, spread it out in a thin layer. The foreign matter was detected by inspection with the unaided eye or by the use of a lens of $6 \mathrm{x}$. Separated, weighed and calculated the percentage of foreign matters present.

Total Ash: The residue remaining after incineration is the ash content of the dry plant material. It is the measure of the total amount of material remaining after incineration. An electric muffle furnace, capable of maintaining a temperature of $625 \pm 25$ ${ }^{\circ} \mathrm{C}$ used for detecting ash content.

Ash content $(\%)=(C-A) /(B-A) X 100$.

Where: $\mathrm{A}=$ weight of empty crucible in $\mathrm{g}, \mathrm{B}=$ weight of crucible and sample,

$\mathrm{C}=$ weight after incineration in $\mathrm{g}$.

Acid Insoluble Ash: It is the residue obtained after boiling the total ash with dilute $\mathrm{HCl}$ and igniting the remaining insoluble matter. This measures the amount of silica present, especially as sand and siliceous earth. Boiled the ash obtained for 5 min with $25 \mathrm{ml}$ of dilute $\mathrm{HCl}$, collected the insoluble matter in an ashless filter paper, washed with hot water and ignited to constant weight and calculated the percentage of acid-insoluble ash.

Water Soluble Extractive: $5 \mathrm{~g}$ of air dried drug was macerated, coarsely powdered with $100 \mathrm{ml}$ of water in a flask for $24 \mathrm{~h}$, shaking frequently during $6 \mathrm{~h}$ and allowed to stand for $18 \mathrm{~h}$. Filtered and evaporated $25 \mathrm{ml}$ of the filtrate to dryness in a tarred flat bottomed shallow dish and dried at $105^{\circ} \mathrm{c}$ to constant weight and weighed. The percentage of water-soluble extractive was calculated with reference to the air-dried drug.

Alcohol Soluble Extractive: $5 \mathrm{~g}$ of air dried drug was macerated, coarsely powdered with $100 \mathrm{ml}$ of Alcohol of specified strength in a closed flask for $24 \mathrm{~h}$, shaking frequently during $6 \mathrm{~h}$ and allowed to stand for $18 \mathrm{~h}$. Filtered rapidly, taking precautions against loss of solvent, evaporated $25 \mathrm{ml}$ of the filtrate to dryness in a tarred flat bottomed shallow dish and dried at $105^{\circ}$ to constant weight and weighed. The percentage of alcohol-soluble extractive was calculated with reference to the air-dried drug.

Loss On Drying Or Moisture Content: It is the amount of water or volatile content present in the sample. Plant material may get spoiled by microbial attack if more moisture is present The plant materials were weighed, kept in an oven at $105^{\circ} \mathrm{C}$ and equilibrated. It was weighed again until three constant readings.

Microbial Safety Profile: All the raw materials must be free from microbial contamination. It is the major safety parameter to ensure the product quality. Microbial screening was carried out to estimate the number of viable microorganisms present in the material. Various differential and selective medias were utilized for screening microbial contamination. For Total viable count (Casein soyabean digestagar), Totalyeast and moulds (Saboraud's dextrose agar with antibiotics), E.coli (MaConkey agar and EMB agar), Salmonella (Brilliant Green agar) Staphylococcus sp. (Mannitol salt agar) Pseudomonas aeruginosa, (Cetrimide agar) was used to screen the organisms as per the AYUSH guidelines.

\section{Development Of Quality Control Parameters For Der- moshine}

Composition And Preparation Of Capsule: All the plant materials as mentioned above were mixed thoroughly using butterfly mixture and made $500 \mathrm{mg}$ of polyherbal hard gelatin capsule (' 0 'size) by using semi-automated capsule filling machine.

Organoleptic Characters: Texture, Color, Odor And Taste Were Assessed By Using Sensory Organs

pH: After preparing 5\% solution of the finished product, the $\mathrm{pH}$ was checked by using digital $\mathrm{pH}$ meter.

Microscopic Characteristics: The powdered materials were spread as thin film on glass slide and observed the shape of the granules under microscope.

Observations Under UV Light: The materials were mixed with $10 \% \mathrm{NaOH} \& 5 \% \mathrm{HCl}$ and observed under UV light at 254 $\mathrm{nm}$ and also observed without adding above constituents.

Weight Variation Test: Test For Uniformity of Weight Was Performed As Per IP 2007. Randomly Selected 20 Capsules Were Weighed (Individually And Together). The Average Weight

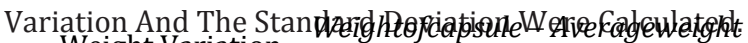

Weight Variation $=\frac{\text { heightofdapsue }}{\text { Averageweightofcapsule }} \mathrm{X} 100$

Drug Content Uniformity: Test for drug content was carried out as per IP. 20 capsules were taken and emptied their content in a mortar and pestle and ground to fine powder; from this $500 \mathrm{mg}$ of powder was taken into a volumetric flask and diluted with phosphate buffer ( $\mathrm{pH}$ 6.8). The absorbance of the solution was measured at $213 \mathrm{~nm}$ by using UV-Visible spectrophotometer (Systronics, UV-Vis Spectrophotometer) [13].

Disintegration: This test is useful as a quality assurance tool for conventional dosage forms. The efficacy of a drug can be dependent on the rate which the capsule disintegrates in the patient's gastrointestinal tract. The disintegration test is a measure of the time required under a given set of conditions for six randomly selected capsules to disintegrate into particles which will pass through a 10 mesh screen with in a disintegration assembly at maintained temperature $37 \pm 2^{\circ} \mathrm{O}$. Disintegration test was performed using the disintegration test apparatus [14].

Flow Properties: Flow properties of drug indicate the uniformity of the granules and it is useful for proper filling and clinical application. The following methods like Angle of repose, Bulk density, Tapped density, Carr`s index, Hausner's ratio and porosity was assessed by standard methods

Angle of Repose: A funnel was fixed at a particular height on a burette stand. A white paper was placed below the funnel on the table. The powdered drug $(5 \mathrm{~g})$ passed slowly through the funnel until it forms a pile. The radius of the pile was noted down. Angle of repose of the powder material was calculated by using the formula: $\tan \theta=h / r ; \theta=\tan (h / r)$ where, $h=$ height of the pile, $r=$ radius. 
Bulk Density (DO): $25 \mathrm{~g}$ of accurately weighed powder was poured into a graduated cylinder, powder bed was made uniform without disturbing the cylinder and the volume was measured directly from the graduation mark on the cylinder as $\mathrm{ml}$ [15]. The volume measured was bulk volume and bulk density is calculated.

$$
\text { Bulk density }=\frac{\text { weight of the powde }}{\text { Bulk volume }}
$$

Tapped Density (Df): After Measuring DO Same Cylinder Was Set To Measure Tapped Density [15]. The Cylinder Was Tapped With 100 Tap Drop/Minute And Operated For 500 Taps. Volume Was Noted As Va, Tapping Was Done Again For 750 Times And Final Volume Was Noted As Vb. The Difference Between Va And Vb Was Calculated And When It Was Found To Be Not More Than $2 \%$, Then Vb Was Considered As Final Tapped Volume And Tapped Density Was Calculated Using The Following Formula

Compressibility Indices: The bulk and tapped densities were used to calculate the compressibility indices (Carr's index and Hausner's ratio) which provide the flow properties and compressibility of powders.

$$
\begin{aligned}
& \text { Hausner's ratio }=\frac{\text { Tapped density }}{\text { Bulk density }} \\
& \text { Carr's index }=\frac{\text { Tapped density }- \text { Bulk density }}{\text { Tapped density }} \mathrm{X} 100
\end{aligned}
$$

Microbial Analysis: Microbial analysis was carried for capsule as per procedures of IP 2007 and WHO Guideline. The test included total bacterial count, total yeast and mould count, identification of specified organism such as Escherichia coli, Salmonella sp., Staphylococcus aureus and Pseudomonas aeruginosa.

\section{Test For Heavy Metals}

Preparation Of Samples By Acid Digestion Method: Accurately weighed $2 \mathrm{~g}$ of sample was taken in Kjeldahl flask. Acid mixture of $\mathrm{HNO}_{3} \mathrm{HClO}_{4}$ (4:1) was added in the flask and heated continuously till the solution is colourless. The sample was then transferred to a $25 \mathrm{ml}$ volumetric flask and the volume was made-up with distilled water. Reagent blank was synchronously prepared according to the above procedure. The standards of lead $(\mathrm{Pb})$, cadmium $(\mathrm{Cd})$, arsenic (As) and mercury $(\mathrm{Hg})$ were prepared as per the protocol in the manual. The samples were analyzed for the presence of $\mathrm{Pb}, \mathrm{Cd}$, As and $\mathrm{Hg}$ using Atomic Absorbance Spectrophotometer (AAS) 6300 (by SHIMADZU) (Lohar, 2007).

\section{Results And Discussion}

Polyherbal formulations can be better than any single chemical entity in many medical conditions. The multi-valent and multi-target actions of mixture of phytochemicals and standardized extracts could provide therapeutic superiority compared to single drug. Now, it is increasingly recognized that, in most disease conditions (e.g. arthritis, liver diseases, radiation induced injuries, old age related diseases and diabetes mellitus), combination therapy is more suitable compared to monosubstance therapy. It is considered that complex physiological processes of the body can be influenced more effectively with less adverse side effects by a combination of several low dose compounds than by a single high dose compound [16] Various types of herbal medicines have been used as curative agents in different parts of the world [17]. Drugs derived from various plant materials may have possible therapeutic relevance in the treatment of illness [18].

In the present study Dermoshine has been taken for the development of quality control parameters as per Ayurveda, Siddha \& Indian pharmacopeias, followed by AYUSH and WHO guidelines.

\section{Raw Materials Identity And Purity}

All the raw materials were screened individually for its identity \& purity and the specifications found within the limits (Table-1). Ash contents are less than the standard value, which indicates the less contamination. Moisture content found to be less than $5 \%$ which is a good indicator for less susceptibility for microbial contamination. Microbial screening was within specified limits and this shows the cleanliness of raw material and good storage practice in the manufacturing premises.

\section{Development of Quality Control Parameters}

The Capsule Was Evaluated By Different Pharmacopeial And Non-Pharmacopeial, Physicochemical Tests Such As Organoleptic Characters, Ph, Flow Properties, Weight Variation, Moisture Analysis, Drug Content Uniformity And Disintegration. The Ph Of 5\% W/V Solution Was 5.53 And Other Physiocochemical Properties Of The Finished Products Were Also Carried Out (Table-2). The IP Limit For Weight Variation In Case Of Capsule Weighing More Than $300 \mathrm{Mg}$ Is $\pm 5 \%$. The Result Shows The Weight Variation of Liverem Capsules Found To Be Within The IP Limit. The Moisture Content Was Less Than 5\%; The Drug Content Uniformity Also Found Within IP Limit. The Disintegration Time Was Found To Be An Average Of 5 Min \& 45 Sec. Flow Properties Like Bulk Density, Tapped Density, Hausner's Ratio, Carr'S Index And Angle Of Repose Were Found To Be $0.92 \mathrm{G} / \mathrm{Cm}^{3}, 1.02 \mathrm{~g} / \mathrm{Cm}^{3}$, 1.10, 9.80 And $34.6^{\circ}$ Respectively. (Table-3). Value Of Carr's Index Below 15 Indicate Excellent Flowing Material And Value Over 20-30 Suggested Poor Flowing Material. Values For Angle Of Repose Less Than $30^{\circ}$ Usually Indicate A Free Flowing Material And Angle Of Repose Greater Than $40^{\circ}$ Suggest A Poor Flowing Material [11].

\section{Microbial Screening Of Dermoshine Capsule}

The Microbial Screening Results Of The Formulation Were Given In Table 4. The Total Aerobic, Yeast And Mould Count Were Found To Be 100cfu/G And 10cfu/G Respectively. Remaining Microbes Like Escherichia Coli, Salmonella Sp. Staphylococcus Aureus Pseudomonas Aeruginosa Were Found Absent.

\section{Heavy Metals Screening Of Dermoshine Capsule}

Screening of heavy metals in traditional system of medicine is an important criterion for the sake of prevention of heavy metal 


\begin{tabular}{|c|c|c|c|c|c|c|c|c|c|c|c|c|c|}
\hline \multirow{2}{*}{ S. No } & \multirow{2}{*}{ Specification } & \multicolumn{2}{|c|}{$\begin{array}{c}\text { Andrographis } \\
\text { paniculata }\end{array}$} & \multicolumn{2}{|c|}{ Azadirachta indica } & \multicolumn{2}{|c|}{$\begin{array}{l}\text { Phyllanthus } \\
\text { amarus }\end{array}$} & \multicolumn{2}{|c|}{$\begin{array}{c}\text { Aristolochia } \\
\text { bracteata }\end{array}$} & \multicolumn{2}{|c|}{ Curcuma longa } & \multicolumn{2}{|c|}{$\begin{array}{l}\text { Hemidesmus } \\
\text { indicus }\end{array}$} \\
\hline & & API (\%) & Result & API (\%) & Result & API (\%) & Result & API (\%) & Result & API (\%) & Result & API (\%) & Result \\
\hline 1 & Foreign matter & NMT 2 & 0.8 & NMT 2 & 0.2 & NMT 2 & 0.4 & NMT 2 & 0.6 & NMT 2 & 0.7 & NMT 2 & 1.6 \\
\hline 2 & Total ash & NMT 11 & 8 & NMT 10 & 6.62 & NMT 16 & 7.20 & NMT 4 & 3.3 & NMT 9 & 6.44 & NMT 4 & 3.6 \\
\hline 3 & Acid insoluble ash & NMT 1 & 0.5 & NMT 1 & 0.6 & NMT 7 & 2 & NMT 1 & 0.4 & NMT 1 & 0.6 & NMT 0.5 & 0.4 \\
\hline 4 & $\begin{array}{l}\text { Water soluble } \\
\text { Extractive }\end{array}$ & NLT 20 & 25.4 & NLT 19 & 22.5 & NLT 13 & 17.92 & NLT 3 & 12.1 & NLT 12 & 13 & NLT 13 & 20.41 \\
\hline 5 & $\begin{array}{l}\text { Alcohol soluble } \\
\text { Extractive }\end{array}$ & NLT 12 & 14.2 & NLT 13 & 15.2 & NLT 3 & 8 & NLT 2 & 6.4 & NLT 8 & 9.5 & NLT 15 & 16 \\
\hline 6 & Volatile oil \% & - & - & - & - & - & - & - & - & NLT 4 & 4.5 & - & - \\
\hline 7 & LOD \% & $<5$ & .1 & $<5$ & 4.3 & $<5$ & 3.5 & $<5$ & 4.2 & $<8$ & 7.4 & $<5$ & 4.1 \\
\hline 8.a & $\begin{array}{l}\text { Microbial -TVC } \\
(\mathrm{CFU} / \mathrm{g})\end{array}$ & $1 \times 10^{5}$ & 90 & $1 \times 10^{5}$ & 105 & $1 \times 10^{5}$ & 95 & $1 \times 10^{5}$ & 94 & $1 \times 10^{5}$ & 80 & $1 \times 10^{5}$ & 98 \\
\hline $\mathrm{b}$ & $\begin{array}{l}\text { Total Yeast \& } \\
\text { Mould (CFU/g) }\end{array}$ & $1 \times 10^{3}$ & $<10$ & $1 \times 10^{3}$ & $<10$ & $1 \times 10^{3}$ & $<10$ & $1 \times 10^{3}$ & $<10$ & $1 \times 10^{3}$ & $<10$ & $1 \times 10^{3}$ & $<10$ \\
\hline c & E. coli & Absent & $\mathrm{Ab}$ & Absent & $\mathrm{Ab}$ & Absent & $\mathrm{Ab}$ & Absent & $\mathrm{Ab}$ & Absent & $\mathrm{Ab}$ & Absent & $\mathrm{Ab}$ \\
\hline $\mathrm{d}$ & Salmonella.sp & Absent & $\mathrm{Ab}$ & Absent & $\mathrm{Ab}$ & Absent & $\mathrm{Ab}$ & Absent & $\mathrm{Ab}$ & Absent & $\mathrm{Ab}$ & Absent & $\mathrm{Ab}$ \\
\hline e & Staphylococcus & Absent & $\mathrm{Ab}$ & Absent & $\mathrm{Ab}$ & Absent & $\mathrm{Ab}$ & Absent & $\mathrm{Ab}$ & Absent & $\mathrm{Ab}$ & Absent & $\mathrm{Ab}$ \\
\hline $\mathrm{f}$ & Pseudomonas sp. & Absent & $\mathrm{Ab}$ & Absent & $\mathrm{Ab}$ & Absent & $\mathrm{Ab}$ & Absent & $\mathrm{Ab}$ & Absent & $\mathrm{Ab}$ & Absent & $\mathrm{Ab}$ \\
\hline
\end{tabular}

Table 2: Organoleptic \& other characters of polyherbal capsule Dermoshine

\begin{tabular}{|l|l|l|}
\hline S. No & Characteristics & Batch: 09008 \\
\hline 1 & Texture & Fine powder \\
\hline 2 & Color & Greenish brown \\
\hline 3 & Odor & Indistinct \\
\hline 4 & Taste & Slightly Bitter \\
\hline 5 & pH (5\%) & 5.53 \\
\hline 6 & Under UV light & Greenish brown \\
\hline
\end{tabular}

Table - 3: Quality control parameters for polyherbal capsule Dermoshine

\begin{tabular}{|l|l|l|}
\hline \multicolumn{1}{|c|}{ S. No } & \multicolumn{1}{|c|}{ Characteristics } & \multicolumn{1}{c|}{ Batch: 09009} \\
\hline 1 & Weight variation & Within IP limit \\
\hline 2 & Moisture analysis \% & 4.5 \\
\hline 3 & Drug content & Within IP limit \\
\hline 4 & Disintegration $(\mathrm{Sec})$ & 345 \\
\hline 5 & Angle of Repose $\left.{ }^{\circ}\right)$ & 34.6 \\
\hline 6 & Bulk Density $\left(\mathrm{g} / \mathrm{cm}^{3}\right)$ & 0.92 \\
\hline 7 & Tap density $\left(\mathrm{g} / \mathrm{cm}^{3}\right)$ & 1.02 \\
\hline 8 & Hausner's ratio & 1.10 \\
\hline 9 & Carr's index & 9.80 \\
\hline
\end{tabular}

Table- 4: Microbial analysis of dermoprotective polyherbal capsule - Dermoshine.

\begin{tabular}{|c|l|l|}
\hline S.No. & \multicolumn{1}{|c|}{ Characteristics } & \multicolumn{1}{|c|}{ Batch: 09009 } \\
\hline 1 & Total Bacterial count & $<100 \mathrm{cfu} / \mathrm{g}$ \\
\hline 2 & Total Yeast \& Mould & $<10 \mathrm{cfu} / \mathrm{g}$ \\
\hline 3 & Escherichia coli & \\
\hline 4 & Salmonella sp & \\
\hline 5 & Staphylococcus sp & \\
\hline 6 & Pseudomonas sp & \\
\hline
\end{tabular}

Table-5: Screening of heavy metals in dermoprotective polyherbal capsule - Dermoshine.

\begin{tabular}{|r|l|l|}
\hline S.No. & \multicolumn{1}{|c|}{ Characteristics } & Batch: 09009 \\
\hline i & Mercury (1 ppm) & \\
ii & Lead (10 ppm) & Within limit \\
\hline iii & Cadmium (0.3 ppm) & \\
\hline iv & Arsenic (3 ppm) & \\
\hline & & \\
\end{tabular}

toxicity. Their presence will cause toxic effect in the body and also causes some genetic variations [19]. Therefore, the formulation was checked for the presence of heavy metal contents namely $\mathrm{Pb}, \mathrm{Cd}, \mathrm{As}$ and $\mathrm{Hg}$ and the results were shown in Table 5. The results indicated that none of the heavy metals detected, exceed their respective permitted level. 


\section{Conclusion}

The present investigation was carried out to develop quality control parameters for a dermoprotective polyherbal formulation Dermoshine. All the raw materials were analysed for its quality, based on the specifications given by Ayurvedic Pharmacopeia of India, Department of AYUSH and WHO guidelines. The results of the product indicate good quality and meet the requirements. Finished product as hard gelatin capsule was evaluated by pharmacopeial and non-pharmacopeial parameters which were found to be good flow properties; microbial and heavy metal screening found within the specified limits. Further research on marker Compounds analysis, Toxicological and Pharmacological evaluation is in progress.

\section{References}

1. Hsu M-F, Chiang B-H. Stimulating effects of Bacillus subtilis nattofermented Radix astragali on hyaluronic acid production in human skin cells. J Ethnopharmaco. 2009;125(3):474-481. doi: 10.1016/j. jep.2009.07.011.

2. Wang K-H, Lin R-D, Hsu F-L, Huang $\mathrm{Y}-\mathrm{H}$, Chang H-C, Huang C-Y, et al. Cosmetic applications of selected traditional Chinese herbal medicines. J Ethnopharmacol. 2006;106(3):353-359.

3. Sumantran VN, Kulkarni AA, Harsulkar A, Wele A, Koppikar SJ Chandwaskar R, et al. Wagh UV: Hyaluronidase and collagenase inhibitory activities of the herbal formulation Triphala guggulu. J Biosci. 2007;32(4):755-761.

4. Mukherjee PK, Maity N, Nema NK, Sarkarm BK. Bioactive compounds from natural resources against skin aging. Phytomedicine. 2011;19(1):64-73.

5. Manuskiatti W, Maibach H. Hyaluronic acid and skin: wound healing and aging. Int J Dermatol. 1996;35(8):539-544.

6. Sharma AK, Gaurav SS, Balkrishna A. A rapid and simple scheme for the standardization of polyherbal drugs. Int J Green Pharm. 2009;3(2):134-140.

7. Ahmad I, Aqil F, Owais M. Turning medicinal plants into drugs. Modern
Phytomed 2006;384:67-72.

8. The Ayurvedic Pharmacopeia of India, Department of AYUSH. Govt. of India. 2007.

9. The Siddha Pharmacopeia of India, Department of AYUSH. Govt. of India. 2008.

10.World Health Organization. Quality control methods for medicinal plant materials. WHO press. 1998.

11. Indian Pharmacopeia, The Indian Pharmacopeial Commission, Govt of India. 2007

12.Dr. DR Lohar. Protocol for testing Ayurveda, Siddha \& Unani Medicines. Pharmacopeial Laboratory for Indian Medicines. Dept of AYUSH, GOVT. of India. 2008.

13. Ramaiah M, Chakravathi G, Yasaswini K. In vitro biological standardization, formulation and evaluation of directly compressed polyherbal anthelmintic tablets. Pharmacognosy J. 2013;5(3):130134

14. Allen Jr LV. The Art, Science, and Technology of Pharmaceutical Compounding. Edn 3, Washington DC: American Pharmacists Association, Washington, DC. 2009;73(3):39.

15. Lachman L, Liebermann HA, Kanig JL. The Theory And Practice of Industrial Pharmacy. Mumbai, India, Varghese Publishing House. 1986;pp.902

16. A Subramoniam. Present scenario, challenges and future perspectives in plant based medicine development. Annals of Phytomedicine; 2014 3(1): 31-36

17. Beaubrum G, Gray GE. A review of herbal medicines for psychiatric disorders. Psychiatr Serv. 2000; 51(9):1130-4.

18. Chawla S, Sharma AK, Handa SS, Dhar KL. Chemical Investigation and anti-inflammatory activity of Vitex negundo seeds: Part I. Indian J chem. 1992;55(2):163:167.

19. Chui SH, Wong YH, Chio HI, Fong MY, Chiu YM, Szeto et al. Study of heavy metal poisoning in frequent users of Chinese medicines in Hong Kong and Macau. Phytother Res. 2013;27(6):859-63. 